\title{
Post Irradiation Evaluation of Thermal Control Coatings and Solid Lubricants to Support Fission Surface Power Systems
}

\author{
Cheryl L. Bowman ${ }^{1}$, Donald A. Jaworske ${ }^{1}$, Malcolm K. Stanford ${ }^{1}$, Justin A. \\ Persinger $^{2}$, Behrooz Khorsandi ${ }^{2}$, and Thomas E. Blue ${ }^{2}$ \\ ${ }^{i}$ NASA Glenn Research Center at Lewis Field, Cleveland, OH 44135 \\ ${ }^{2}$ Department of Mechanical Engr., Nuclear Engr. Program, The Ohio State Univ., Columbus, OH $432 \mathrm{JO}$ \\ 216-433-8462; Cheryl.L.Bowman@nasa.gov
}

\begin{abstract}
The development of a nuclear power system for space missions, such as the Jupiter Icy Moons Orbiter or a lunar outpost, requires substantially more compact reactor design than conventional terrestrial systems. In order to minimize shielding requirements and hence system weight, the radiation tolerance of component materials within the power conversion and heat rejection systems must be defined. Two classes of coatings, thermal control paints and solid lubricants, were identified as material systems for which limited radiation hardness information was available. Screening studies were designed to explore candidate coatings under a predominately fast neutron spectrum. The Ohio State Research Reactor Facility staff performed irradiation in a well characterized, mixed energy spectrum and performed post irradiation analysis of representative coatings for thermal control and solid lubricant applications. Thermal control paints were evaluated for $1 \mathrm{MeV}$ equivalent fluences from $10^{13}$ to $10^{15} \mathrm{n} / \mathrm{cm}^{2}$. No optical degradation was noted although some adhesive degradation was found at higher fluence levels. Solid lubricant coatings were evaluated for $1 \mathrm{MeV}$ equivalent fluences from $10^{15}$ to $10^{16} \mathrm{n}^{/} \mathrm{cm}^{2}$ with coating adhesion and flexibility used for post irradiation evaluation screening. The exposures studied did not lead to obvious property degradation indicating the coatings would have survived the radiation environment for the previously proposed Jupiter mission. The results are also applicable to space power development programs such as fission surface power for future lunar and Mars missions.
\end{abstract}

Keywordst heat rejection systems, thermal control surfaces.

PACS: 78.20.-e.

\section{BACKGROUND}

The proposed Jupiter Icy Moons Orbiter (JIMO) program had both the challenge of designing a compact fastspectrum fission heat source as well as developing power conversion and heat rejection components tolerant of the radiation spectrum. From the preliminary spacecraft design specifications, the neutron and gamma flux distribution along the length of the vehicle was estimated. The neutron fluence was estimated to be around $10^{12}$ to $10^{13}$ neutrons $/ \mathrm{cm}^{2}$ for the power conversion system and $10^{11}$ to $10^{12} \mathrm{n} / \mathrm{cm}^{2}$ for the heat rejection system. Traditional structural metallics and ceramics can withstand fluences of $10^{17} \mathrm{n} / \mathrm{cm}^{2}$ at energies greater than $1 \mathrm{MeV}$ before structural integrity is impaired implying that the power conversion and heat rejection structural materials would not be at risk. However, polymer materials can undergo either softening or embrittlement at lower fluences. Unfortunately much of the irradiation literature does not describe the energy spectrum used for exposure in a manner conducive to comparisons with a candidate, fast-reactor spectrums. It is therefore difficult to make judgments about generic mission survivability of components that relay on polymers for part of their functionality. The goal of this research was to expose representative specimens in a well-characterized, high energy neutron spectrum. A screening study has been performed to evaluate possible radiation-induced degradation in candidate thermal control coatings and solid lubricant coatings that were applied in prototypic thickness on candidate substrates. 
Thermal control paints and solid lubricants both represent thin coatings that often rely on polymers as part of their functionality. In the case of thermal control coatings, both changes in the optical properties, as well as adhesion degradation, would be of concern for long term operation. For solid lubricants, the friction and wear properties of the coatings are the most relevant post-irradiation response. However wear testing of activated coatings has a high probability of producing fine, radioactive contamination necessitating the development of a dedicated, high temperature wear testing facility. Therefore, coating adhesion was used in these experiments to screen the radiation hardness of coatings.

Also of concern for surface components, such as paints, would be the trapped electron and proton fluences that were estimated to be on the order of $5.2 \times 10^{14}$ ( $1 \mathrm{MeV}$ electrons), $2.2 \times 10^{11}$ (100 MeV electrons), $4.5 \times 10^{14}$ ( $1 \mathrm{MeV}$ protons), and $5.5 \times 10^{10}$ (100 MeV protons) from the JIMO Second Technical Baseline estimates. The influence of electron dose accumulation has been discussed (Willis, 2004). But the proton dose accumulation is also significant, and some suggest that proton dose accumulation can be simulated through the use of neutrons, owing to their similar mass.

\section{MATERIALS AND METHODS}

\section{Irradiation Exposure Conditions}

Samples described in the subsequent sections were exposed at the Ohio State University Nuclear Reactor Laboratory. The Ohio State University Research Reactor (OSURR) is a pool-type reactor that is utilized for a variety of instructional, research, and service activities. It is licensed to operate at continuously variable thermal power up to a maximum of 500 kilowatts, and at maximum steady-state power, the average thermal neutron flux in the core is approximately $5 \times 10^{12} \mathrm{n} / \mathrm{cm}^{2} / \mathrm{s}$. The reactor is immersed in a pool of light water that provides moderation and cooling by natural convective flow. These experiments employed Beam port \#1, which has a $15.25 \mathrm{~cm}$ diameter, is aligned perpendicularly with the core center, has a $7.8 \times 10^{12} \mathrm{n} / \mathrm{cm}^{2} / \mathrm{s}$ maximum total flux, and $4.5 \times 10^{12}$ $\mathrm{n} / \mathrm{cm}^{2} / \mathrm{s}$ maximum thermal flux. A special sample chamber was employed that allowed active pumping during the irradiation. Equivalent, out-of-core vacuum, calibration demonstrated that a vacuum of 0.3 Torr \pm 0.07 Torr could be maintained.

Because the effects of high energy, fast spectrum neutrons were the focus of this test program, the specimen chamber utilized a beam port fixture that incorporated cadmium shielding to reduce the thermal neutron flux. Prior to specimen exposure, the neutron flux was characterized within the vacuum chamber and shielding in terms of a reference energy $E_{\text {ref }}=1 \mathrm{MeV}$ and using iron $(\mathrm{Fe})$ as the reference material. Using the guidelines of ASTM specification E722, $\phi_{e q, 1 \mathrm{MoV}, F_{e}}^{\text {Tolal }}$ is a suitable parameter to compare damage created by two or more fluences on the same material. Table 1 presents the total (integrated over the entire spectra) neutron flux, total neutron flux for 1 MeV reference energy in iron, energy-spectrum hardmess parameter, and damage rate calculated according to ASTM specifications $\mathrm{E} 722$ and $\mathrm{E} 693$ using flux wire exposures at a reference reactor power level of $500 \mathrm{~kW}$. The flux wire measurements were performed inside the specimen chamber, with the cadmium shielding in place, next to surrogate specimens, and while the specimen chamber was located at a fixed distance relative to the reactor core. The values presented in Table I were used to calculate the exposure levels for subsequent specimen testing. All samples were located in the chamber to keep the fluence as constant as possible within tests-comparison groups. Specimen self heating was monitored by attaching thermal couples to surrogate specimens located outside the vacuum chamber but inside the cadmium shielding. The maximum temperature observed was $55^{\circ} \mathrm{C}$ for a stainless steel specimen and $50^{\circ} \mathrm{C}$ for a superalloy foil after 6 hours at $100 \mathrm{~kW}$ (reactor power). Additional details on spectrum characterization as well as other test methods were discussed elsewhere (Blue, 2006).

TABLE 1. Calculated Neutron Flux, $1 \mathrm{MeV}$ Equivalent Neutron Flux, Energy-Spectrum Hardness Parameter, and Damage Rate at $500 \mathrm{~kW}$ Reference Reactor Power Level.

\begin{tabular}{ccccc}
\hline Location & $\phi^{\text {Total }}\left(\mathrm{cm}^{-2} \mathrm{~s}^{-1}\right)$ & $\phi_{\text {eq, } 1 \text { MeV }, F e}^{\text {Total }}\left(\mathrm{cm}^{-2} \mathrm{~s}^{-1}\right)$ & $\mathbf{H}_{\mathrm{Fe}}$ & $\begin{array}{c}\text { Damage Rate } \\
\left(\mathbf{d p a}_{\mathrm{Re}} / \mathrm{s}\right)\end{array}$ \\
\hline OSURR BP1 Front & $1.45 \times 10^{12}$ & $1.60 \times 10^{12}$ & 1.10 & $7.96 \times 10^{-10}$ \\
OSURR BP1 Back & $6.71 \times 10^{14}$ & $7.32 \times 10^{11}$ & 1.09 & $3.65 \times 10^{-10}$ \\
\hline
\end{tabular}




\section{Thermal Control Coatings}

Previous work has identified the importance of utilizing an epoxy interface layer between thermal control paint and the underlying polymer matrix composite (Jaworske, 2005 and Jaworske, 2006). Use of the epoxy layer provides good adhesion as determined by the ASTM D-3359 test method A. From the suite of commercial thermal control paints currently available, two typical paints utilizing an epoxy interface were selected for neutron exposure. The first was a white thermal control paint identified as AZ-93, a non conductive formulation using zinc oxide pigment in a potassium silicate binder, manufactured by $\mathrm{AZ}$ Technology (Huntsville, AL), designated here as surface treatment $\mathrm{A}$. The second paint was a black thermal control paint identified as RM550, also manufactured by $A Z$ Technology, designated here as surface treatment $B$. The paint was applied to approximately $5 \mathrm{~cm} \times 5 \mathrm{~cm}$ coupons of three different composite types. First was a carbon-carbon product manufactured by C-CAT (Carbon-Carbon Advanced Technologies), Inc., Fort Worth, TX, made by a resin infiltration and pyrolysis process, and designated here as CC. Second was a carbon-carbon product manufactured by BF Goodrich Corp., Santa Fe Springs, CA. This composite, designated here as $\mathrm{BF}$, is made by high temperature pitch impregnation and pyrolysis followed by carbon densification using a chemical vapor infiltration process, Third was a carbon-polyimide product, designated here as PC, manufactured at Glenn Research Center as part of an ongoing research effort. Coated samples were subjected to the neutron exposure conditions summarized in Table 2. Additional coupons were utilized as pristine counterparts for evaluation. The sample nomenclature was composite type-paint type-exposure level. For example, a coupon identified as CC-A-Exp2 corresponds to a coupon manufactured by C-CAT with a white thermal control paint on its surface, and subjected to the highest neutron exposure during testing.

TABLE 2. Irradiation Exposure Conditions for Thermal Control Coating Candidates.

\begin{tabular}{lcc}
\hline & $\operatorname{Exp}$ & Exp2 \\
\hline Operating Power (kW) & 3 & 100 \\
Operating Time (min) & 35 & 100 \\
Fast Neutron Fluence $\left(\mathrm{cm}^{-2}\right)$ & $1.08 \times 10^{13}$ & $1.03 \times 10^{15}$ \\
Neutron Fluence $\left(\mathrm{cm}^{-2}\right)$ & $1.83 \times 10^{13}$ & $1.74 \times 10^{15}$ \\
$\Phi_{\text {eq, IMeV,Fe }}^{\text {Total }}\left(\mathrm{cm}^{-2}\right)$ & $2.02 \times 10^{13}$ & $1.92 \times 10^{15}$ \\
\hline
\end{tabular}

\section{Solid Lubricant Coatings}

The solid lubricant coatings studied were representative of thin films typically applied to foils and the thicker coatings typically applied to journals in gas foil bearing systems used in a closed Brayton cycle rotating assembly. These coatings are required to provide a known, low friction coefficient on shaft start-up. There was a concern that coatings on an idle spare might degrade under long term exposure. To address this concern a range of candidate coatings were explored. Six commercially available thin film, solid lubricant coatings were applied to one side of $2.5 \mathrm{~cm} \times 5.1 \mathrm{~cm}, \mathrm{X}-750$ superalloy foils: Teflon-S fluoropolymer (DuPont Comp.), Emralon 333 fluorocarbon (Acheson Colloids Comp., Port Huron, MI), Xylan 1620 fluoropolymer (Whitford Corp., Frazer, PA), Endura 42010, Endura 440-11 (Endura Coatings, Warren, MD, and Korolon 800 tungsten disulfide (Mohawk Innovative Technology, Inc., Albany, NY). The journal bearing, or thick coating system, studied was PS304. This is a composite coating that is thermal sprayed on to the substrate. The composition of this coating is $60 \mathrm{wt} \%$ nichrome $(80 \mathrm{Ni}-20 \mathrm{Cr}), 20 \mathrm{wt} \%$ chromia $(\mathrm{Cr} 2 \mathrm{O} 3), 10 \mathrm{wt} \%$ silver and $10 \mathrm{wt} \%$ binary eutectic barium fluoride - calcium fluoride (68BaF2-32CaF2). Nichrome is a binder that, along with chromia, provides wear resistance. Silver and BaF2-CaF2 are solid lubricants at low and high temperatures, respectively. An approximately $0.5 \mathrm{~mm}$ PS304 coating was sprayed on $6 \mathrm{~mm}$ thick, $25 \mathrm{~mm}$ diameter, 410 stainless steel coupons. The solid lubricants were subjected to three levels of exposure as listed in Table 3 and 4 . The differences in fluences between Tables 3 and 4 were because the PS304 samples were physically larger than the thin film solid lubricant candidates and thus were located in a different region of the vacuum chamber. 
TABLE 3. Irradiation Exposure Conditions for Thin Film Solid Lubricant Candidates.

\begin{tabular}{lccc}
\hline & Exp3 & Exp4 & Exp5 \\
\hline $\begin{array}{l}\text { Operating Time (hours at 100kW) } \\
\text { Fast Neutron Fluence }\left(\mathrm{cm}^{-2}\right)\end{array}$ & 3 & 6 & 9 \\
Neutron Fluence $\left(\mathrm{cm}^{-2}\right)$ & $8.49 \times 10^{14}$ & $1.70 \times 10^{15}$ & $5.57 \times 10^{15}$ \\
$\Phi_{\text {Total }}^{\text {Tol }}$ & $1.45 \times 10^{15}$ & $2.90 \times 10^{15}$ & $9.40 \times 10^{15}$ \\
\hline
\end{tabular}

TABLE 4. Irradiation Exposure Conditions for PS304 Solid Lubricant Coated Samples.

\begin{tabular}{lccc}
\hline & Exp3 & Exp4 & Exp5 \\
\hline Operating Time (hours at 100kW) & 3 & 6 & 9 \\
Fast Neutron Fluence $\left(\mathrm{cm}^{-2}\right)$ & $1.26 \times 10^{15}$ & $2.51 \times 10^{15}$ & $3.77 \times 10^{15}$ \\
Neutron Fluence $\left(\mathrm{cm}^{-2}\right)$ & $2.13 \times 10^{15}$ & $4.26 \times 10^{15}$ & $6.39 \times 10^{15}$ \\
$\mathbf{\Phi}_{\text {eqtal }}^{\text {Totav, Fe }}\left(\mathrm{cm}^{-2}\right)$ & $2.35 \times 10^{15}$ & $4.70 \times 10^{15}$ & $7.05 \times 10^{15}$ \\
\hline
\end{tabular}

\section{Post Irradiation Evaluation Test Methods}

An SOC-400t infrared reflectometer was modified prior to use by installing a thin silicon wafer over the sample port. The silicon wafer, being significantly transparent in the infrared range of the instrument, 2 to 25 microns, prevented any radioactive particles from entering the instrument, while allowing infrared light from the source to reflect off of the sample and return to the detector. Although there was a minor penalty in signal strength, the modification to the instrument was found to work quite well and the reflectance data from the samples were bracketed by standards to enable subsequent calculation of infrared emittance. Infrared reflectance measurements were made with the modifications in place, before neutron irradiation, for comparison. The thermal control surfaces also were inspected visually for discoloration after irradiation and were photographed. The six sets of sister coupons were photographed simultaneously, under similar lighting conditions, utilizing a digital camera.

Adhesion testing was conducted on pristine (control) and neutron-exposed samples. The adhesion testing was based on ASTM Standard D-3359-02 test method A, the X-cut tape test. The thermal control paint specimens were scribed with two $5 \mathrm{~cm}$ parallel lines approximately $1.5 \mathrm{~cm}$ apart. This variation was used based on past experience in evaluating various thermal control paints. For the thin solid lubricant coatings, a $5 \mathrm{~cm}$ " $\mathrm{X}$ " was scribed onto the coupons. In both cases a scalpel was used to penetrate the substrate in a single cut. Paper backed masking tape ( $3 \mathrm{M}^{\mathrm{TM}} 250$ ) was applied over the scribe marks with four passes of a rubber roller. The tape was applied normal to the two scribed lines for the paints and along the length of the solid lubricant samples. The six point qualitative scale recommended in the test method was used to rate the adhesion. This scale included ratings of 5A "No peeling or removal", $4 \mathrm{~A}$ "Trace peeling or removal along incisions", $3 \mathrm{~A}$ "Jagged removal along incisions up to $1.8 \mathrm{~mm}$ on either side", $2 \mathrm{~A}$ "Jagged removal along most of incisions up to $3.2 \mathrm{~mm}$ on either side", $1 \mathrm{~A}$ "Removal from most of the area under the tape", and $0 \mathrm{~A}$ "Removal beyond the area under the tape". To determine extent of removal, both the sample and the tape were observed and photographed.

The flexibility of the thin solid lubricant coatings was evaluated at toom temperature by bending the coated specimens around a smooth die following the specifications of ASTM Standard D 4145-83. The coated specimens were bent around a die having a thickness of $0.317 \mathrm{~cm}$. The combined thickness of the coating and substrate for the various materials ranged from $0.013 \mathrm{~cm}$ to $0.015 \mathrm{~cm}$. Therefore the die that was utilized produced bends ranging from approximately $21 \mathrm{~T}$ to $25 \mathrm{~T}$ (defined in the standard as die thickness divided by coated specimen thickness). The coating was evaluated for cracking through visual examination and photography. Then the adhesion of the 
coating over the bent area was evaluated through coating pick-off using the tape application and removal process described in the previous paragraph.

The adhesion/cohesion strength of the thick PS304 coating was assessed following the guidelines provided in ASTM Standards C 633-01 and D 4541-02. An Elcometer 110 PATTITM pneumatic adhesion tester with a piston diameter of $146 \mathrm{~mm}$ was used to evaluate the coating adhesion. Coated specimens were bonded to the pull stubs with an epoxy adhesive (Miller-Stephenson's Epoxy 907). Due to the large number of coupons, the samples were bonded and tested in two different batches. Unfortunately there was a discrepancy in epoxy cure conditions between the batches. After proper application of the adhesive, the Batch 1 specimens were allowed to cure at room temperature, $21{ }^{\circ} \mathrm{C}$, for 24 hours and then at $60^{\circ} \mathrm{C}$ for an additional 24 hours. Due to a furnace problem, the batch 2 specimens were cured at some temperature below $60^{\circ} \mathrm{C}$ in the last step.

\section{RESULTS AND DISCUSSION}

\section{Thermal Control Coatings}

The as-painted coupons appeared to have good paint coverage, with the AZ-93 white paint samples appearing bright white and the RM550 appearing pitch black. Paint thickness was estimated to be $0.08 \mathrm{~mm}$. No observable discoloration was observed in the post-irradiated coupons for either surface treatment. All coupons appeared congruent to their pristine counterparts. The photographs of irradiated coupons obtained next to their pristine sister samples are summarized in Figure 1. The images are, from left to right, the pristine specimen, the specimen irradiated at $3 \mathrm{~kW}$, and the specimen irradiated at $100 \mathrm{~kW}$. Although qualitative, no change in appearance to the unaided eye suggests little to no change in the solar absorptance of the thermal control paint under the given neutron irradiation conditions.
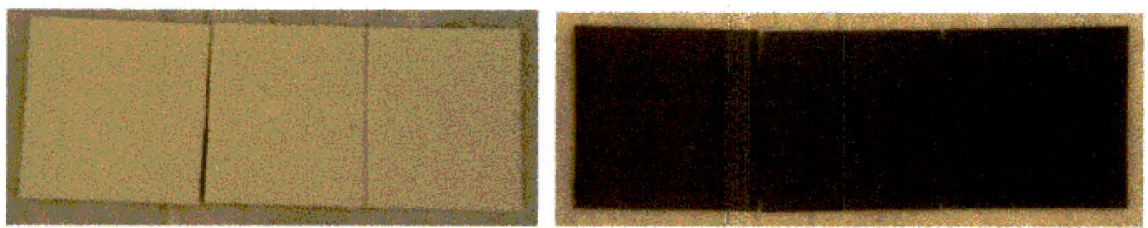

(a) Pristine, CC-A-Exp1, CC-A-Exp2, Pristine, CC-B-Exp1, CC-B-Exp2.
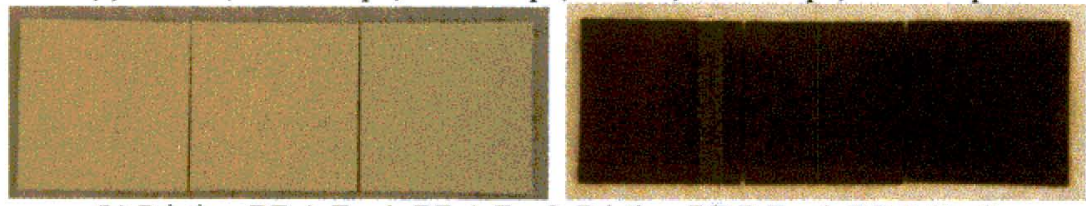

(b) Pristine, BF-A-Exp1, BF-A-Exp2, Pristine, BF-B-Exp1, BF-B-Exp2.
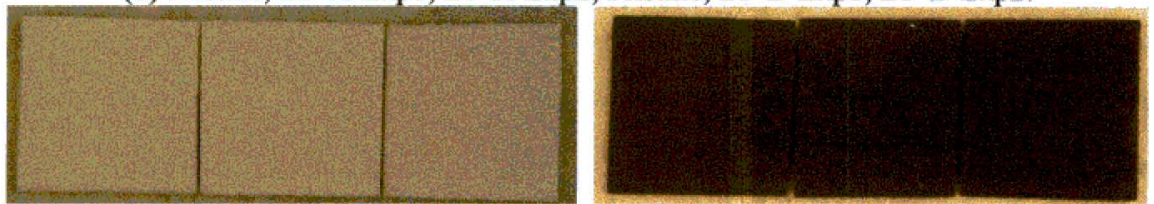

(c) Pristine, PC-A-Exp1, PC-A-Exp2, Pristine, PC-B-Exp1, PC-B-Exp2.

FIGURE 1. Photographs of Pristine and Exposed Coupons After Neutron Exposure.

The initial infrared emittance of each coupon, along with its post neutron exposure infrared emittance, is summarized in Table 5. In general, the calculated values obtained utilizing the silicon wafer modification seem overestimated, but consistent. Typical infrared emittance values for AZ-93 and RM550, as measured by a GierDunkle DB-100, are 0.914 and 0.893 , respectively. The overestimating may be a consequence of utilizing a silicon wafer in the optical path. However, the values in Table 5 are consistent; the pristine values from one sample within a given lot $t$ are similar and, more importantly, the emittance values are similar between pristine and post-irradiated measurements. This observation reinforces the observation made previously suggesting little to no change in optical properties, upon neutron irradiation to the fluence levels used here. 
TABLE 5. Infrared Emittance, at $27^{\circ} \mathrm{C}(300 \mathrm{~K})$, Before (Average of 2 Values) and After Neutron Exposure.

\begin{tabular}{lllllll}
\hline & CC-A & CC-B & BF-A & BF-B & PC-A & PC-B \\
\hline Pristine & 0.976 & 0.958 & 0.979 & 0.962 & 0.978 & 0.987 \\
Expl & 0.974 & 0.953 & 0.975 & 0.954 & 0.977 & 0.984 \\
Exp2 & 0.974 & 0.952 & 0.974 & 0.953 & 0.975 & 0.975 \\
\hline
\end{tabular}

Adhesion testing was conducted on the coupons, both pristine and those exposed to neutrons. The results of the adhesion testing are summarized in Table 6. For Exp1, the experiment with the lower neutron fluence, nearly all coupons had adhesion chatacteristics similat to their pristine counterparts. For Exp2, the experiment with the higher neutron fluence, coupons CC-A, BF-A, PC-A, and CC-B exhibited a decrease in adhesion strength with increased neutron fluence. Coupon BF-B was assessed an adhesion rating of $3 \mathrm{~A}$, at both of the tested fluence levels, and coupon PC-B was assessed a rating of 5A, at both of the tested fluence levels. In general, the results indicate that the adhesion strength of thermal control paint is unaffected by the lower neutron fluence level, however, the adhesion strength is affected by the higher neutron fluence level.

TABLE 6. Adhesion Test Results, Pristine and After Neutron Exposure.

\begin{tabular}{lcccccc}
\hline & CC-A & CC-B & BF-A & BF-B & PC-A & PC-B \\
\hline Pristine & $4 \mathrm{~A}$ & $4 \mathrm{~A}$ & $4 \mathrm{~A}$ & $5 \mathrm{~A}$ & $4 \mathrm{~A}$ & $5 \mathrm{~A}$ \\
Exp1 & $4 \mathrm{~A}$ & $3 \mathrm{~A}$ & $4 \mathrm{~A}$ & $3 \mathrm{~A}$ & $4 \mathrm{~A}$ & $5 \mathrm{~A}$ \\
Exp2 & $3 \mathrm{~A}$ & $2 \mathrm{~A}$ & $3 \mathrm{~A}$ & $3 \mathrm{~A}$ & $3 \mathrm{~A}$ & $5 \mathrm{~A}$ \\
\hline
\end{tabular}

\section{Solid Lubricant Coatings}

Both the thin film solid lubricants and PS304 thermal spray coating survived exposure to $1 \mathrm{MeV}$ equivalent fluence of $\sim 10^{16}$ neutrons $/ \mathrm{cm}^{2}$ with no notable change in appearance. The mechanical survivability of the thin film coatings were assessed through adhesion and flexibility testing, while only adhesion strength results were relevant for the PS304 coating. Three samples, representing each thin film coating and radiation exposure level, were subjected to the tape adhesion testing and the responses are tabulated in Table 7 . No notable peeling was found under any exposure condition for Emralon 333, Xylan 1620, or Endura 440-11. The other three coatings experienced some peeling, but there were no obvious trends with respect to exposure level. The flexibility of two samples, representing each thin film coating and radiation exposure level, were tested and the results are summarized in Table 8. No cracking or pick-off from post-bending tape adhesion testitig was observed for the Teflon-S and Emralon 333 samples and one crack developed in the six Xylan 1620 samples. Cracking and delamination was prevalent in the Endura 440-11 and Korolon 800, but was not apparently a function of accumulated fluence.

Table 7. Tape Adhesion Test Results for Solid Lubricants.

\begin{tabular}{lcccccc}
\hline & Teflon-S & Emralon 333 & Xylan 1620 & Endura 420-10 & Eadura 440-11 & Korolon 800 \\
\hline Exp3 & $4 \mathrm{~A} / 5 \mathrm{~A}$ & $5 \mathrm{~A}$ & $5 \mathrm{~A}$ & $4 \mathrm{~A}$ & $5 \mathrm{~A}$ & $3 \mathrm{~A}$ \\
Exp4 & $4 \mathrm{~A} / 5 \mathrm{~A}$ & $5 \mathrm{~A}$ & $5 \mathrm{~A}$ & $4 \mathrm{~A} / 5 \mathrm{~A}$ & $5 \mathrm{~A}$ & $4 \mathrm{~A} / 5 \mathrm{~A}$ \\
Exp5 & $4 \mathrm{~A} / 5 \mathrm{~A}$ & $5 \mathrm{~A}$ & $5 \mathrm{~A}$ & $4 \mathrm{~A}$ & $5 \mathrm{~A}$ & $3 \mathrm{~A}$ \\
\hline
\end{tabular}

Table 8. Bending Adhesion Test Results for Solid Lubricants; Number of Specimens Experiencing Cracking/Pick-Off.

\begin{tabular}{ccccccc}
\hline & Teflon-S & Emraion 333 & Xylan 1620 & Endura 420-10 & Endura 440-11 & Korolon 800 \\
\hline Exp3 & $0 / 0$ & $0 / 0$ & $0 / 0$ & $1 / 0$ & $2 / 2$ & $2 / 2$ \\
Exp4 & $0 / 0$ & $0 / 0$ & $0 / 0$ & $2 / 2$ & $2 / 2$ & $2 / 2$ \\
Exp5 & $0 / 0$ & $0 / 0$ & $1 / 0$ & $1 / 1$ & $2 / 2$ & $2 / 2$ \\
\hline
\end{tabular}


The PS304 coating adhesion was evaluated by comparing pull-stub strengths as a function of radiation exposure. The resulting failure strengths are given in Table 9. The failure types listed in Table 9 indicated the qualitatively determined percentage of the cohesive failure that occurred within the PS304 coating rather than in the epoxy bonding material. As mentioned in the test methods section, there was a problem with the aging furnace which led to incomplete curing of the adhesive in Batch 2; this poor curing resulted in lower failure strengths and failures that initiated not within the coating. The samples evaluated as part of Batch 1 did not show obvious degradation in failure stress over the irradiation conditions explored.

Table 9. Pull Test Results for PS304 Thermal Spray Solid Lubricant.

\begin{tabular}{|c|c|c|c|c|c|c|}
\hline & \multicolumn{3}{|c|}{ Bateh 1 } & \multicolumn{3}{c|}{ Batch 2 } \\
\hline & $\begin{array}{c}\text { Failure Stress } \\
\text { (MPa) }\end{array}$ & $\begin{array}{c}\text { Std. Dev } \\
\text { (MPa) }\end{array}$ & $\begin{array}{c}\text { Failure } \\
\text { Type }\end{array}$ & $\begin{array}{c}\text { Failure Stress } \\
\text { (MPa) }\end{array}$ & $\begin{array}{c}\text { Std. Dev. } \\
\text { (MPa) }\end{array}$ & $\begin{array}{c}\text { Failure } \\
\text { Type }\end{array}$ \\
\hline Pristine & 15.44 & 0.7 & $90-100 \%$ PS304 & 11.24 & 0.9 & $25-90 \%$ PS304 \\
\hline Exp3 & 15.89 & 2.2 & $90-100 \%$ PS304 & 9.02 & 2.6 & $25-75 \%$ PS304 \\
\hline Exp4 & 15.65 & 2.1 & $90-100 \%$ PS304 & 11.65 & 0.7 & $0-75 \%$ PS304 \\
\hline Exp5 & 14.04 & 1.9 & $90-100 \%$ PS304 & 11.13 & 0.4 & $25-75 \%$ PS304 \\
\hline
\end{tabular}

\section{SUMMARY AND CONCLUSIONS}

Based on preliminary design specifications for a JIMO mission, the neutron fluence along the length of the spacecraft was estimated, and the neutron fluence for the heat rejection system was estimated to be $10^{11}$ to $10^{12}$ $\mathrm{n} / \mathrm{cm}^{2}$. Three candidate polymer matrix composite face sheets considered for use on light weight heat rejection systems, and two candidate thermal control paints applied to such face sheets, were exposed to multiple neutron fluences in excess of the heat rejection system estimate for the purpose of evaluating the optical properties durability of the thermal control paints and the adhesion characteristics of the PMC-epoxy-paint systems. Coupons utilizing an epoxy interface layer were considered solely because previous environmental durability studies indicated poor adhesion characteristics of paints to polymer matrix composites in the absence of an epoxy interface layer. The optical properties evaluated here exhibited little to no change at the two neutron fluences selected for this study, $10^{13}$ and $10^{15}$ (1MeV equivalent) $\mathrm{n} / \mathrm{cm}^{2}$, while the adhesion characteristics of the paint were only deteriorated at the higher neutron fluence.

Preliminary design specifications for a JIMO mission, estimated a $10^{12}$ to $10^{13} \mathrm{n} / \mathrm{cm}^{2}$ fluence in the power conversion equipment region. The mechanical adhesion of candidate solid lubricants were evaluated here from approximately $10^{15}$ to $10^{16}$ (1MeV equivalent) $\mathrm{n} / \mathrm{cm}^{2}$ as a screening study. In general, the coatings exhibited little evidence of degradation in these ranges. Under the conditions studied, the thin film solid lubricants Emralon 333 and Xylan 1620 exhibited the best combination of adhesion and flexibility. Likewise, the thicker $\mathrm{NiCr}$-composite (PS304) solid lubricant showed no statistical cohesive (failure within the coating) or adhesive (bonded to the substrate) strength degradation in this fluence range. It is important to note that the failure strengths measured for the PS304 samples reported here all came from one manufacturing lot, and the strengths are much lower than typical. Previous studies have shown that the failure strength can be optimized through heat treatment (DellaCorte, 2002). Great care was taken to ensure that the test method was followed correctly and control specimens from a different manufacturing lot (none of which were irradiated) resulted in more typical strengths. Future microstructural evaluation of the coatings may reveal the source of the strength discrepancies.

\section{NOMENCLATURE}

$\begin{array}{ll}\mathrm{a} & =\text { albedo } \\ \text { dpa } & =\text { estimated the number of displacements per reference material atom } \\ \mathrm{E}_{\mathrm{ref}} & =\text { reference energy, } 1 \mathrm{MeV} \\ \mathrm{eV} & =\text { electron volt } \\ \mathrm{H}_{\mathrm{mal}} & =\text { energy-spectrum hardness parameter for reference material } \\ \mathrm{JMO} & =\text { Jupiter Icy Moons Orbiter } \\ \mathrm{n} & =\text { neutrons } \\ \text { OSURR } & =\text { Ohio State University Research Reactor }\end{array}$


PMC = polymer matrix composite

$\mathrm{W}=$ watt

$\Phi \quad=$ neutron fluence

\section{ACKNOWLEDGMENTS}

The authors appreciate research support provided by Victor Lukaszewicz at NASA GRC and David Hawn, Jeremy Chenkovich and Viji Krishnan at OSU. This research was supported through the Prometheus Power and Propulsion Program under NASA's Exploration Systems Mission Directorate. Any opinions expressed are those of the authors and do not necessarily reflect the views of NASA, the Department of Energy, or the Prometheus Program.

\section{REFERENCES}

ASTM Standard C 633-01, "Standard Test Method for Adhesion of Cohesion Strength of Thermal Spray Coatings," approved 2001, Annual Book of ASTM Standards, Vol 02.05, West Conshohocken, PA.

ASTM Standard D 3359-02, "Standard Test Methods for Measuring Adhesion by Tape Test," approved 2002, Anntal Book of ASTM Standards, Vol 06.01, West Conshohocken, PA.

ASTM Standard D 4145-83, "Standard Test Method for Coating Flexibility of Prepainted Sheet," reapproved 2002, Anntral Baok of ASTM Standards, Vol 06.02, West Conshohocken, PA.

ASTM Standard D 4541-02, "Standard Test Method for Pull-Off Strength of Coatings Using Portable Adhesion Testers," approved 2002, Annual Book of ASTM Standards, Vol 06.02, West Conshohocken, PA.

Blue, T.E., et al., "Final Report PCHR System Component Materials Testing for Space Nuclear Power," submitted for publication as a NASA contractor report, 2006.

DellaCorte, C., "The Effects of Substrate Material and Thermal Processing Atmosphere on the Strength of PS304: A High Temperature Solid Lubricant Coating," NASA/TM-2002-211483; NASA Center for Aerospace Information, Hanover, MD, (electronically at http://gltrs.grc.nasa.gov), 2002.

Jaworske, D. A., "Electron Beam Exposure of Thermal Control Paints on Carbon-Carbon and Carbon-Polyimide Composites" in Proceedings of 23rd Symposium on Space Nuclear Power and Propulsion, edited by M. El-Genk, AIP Conference Proceedings 813, New York, 2006, pp. 50-55.

Jaworske, D. A., "Thermal Cycling of Thermal Control Paints on Carbon-Carbon and Carbon-Polyimide Composites," presented at 3rd International Energy Conversion Engineering Conference, AIAA-2005-5589, American Institute of Aeronautics and Astronautics, 2005.

Mason, L.S., "A Power Conversion Concept for the Jupiter Icy Moons Orbiter," Joumal of Propulsion and Power, 902-910, (2005).

Willis, P., NASA Jet Propulsion Laboratory, Pasadena, CA, Personal Communication, 2004. 